\title{
SHAFT ALIGNMENT MEASUREMENT SYSTEM DEVELOPED FOR INDUSTRIAL APPLICATIONS
}

\section{Iván Mendoza y Grover Zurita}

\begin{abstract}
In the industry, the shaft misalignment is considered a common fault in rotating machines. Inadequate alignment of rotating shafts through couplings often lead to severe vibration complications with premature failure of machines parts. It is, without uncertainty, the greatest loss of profits allocated to misalignment, resulting limited production, increasing energy cost, increasing downtime and premature breakdown of the equipment. It's of a big paramount to optimize the rotating machines efficiency by an appropriate alignment technique. Therefore, from aforementioned, the main objective of this research work is to develop a low-cost, with high precision shaft alignment measurement system for industrial applications. The developed prototype was based on an inductive sensor system, which is a non-contacting and electronic dial indicator equipment. It was used an Arduino Uno for the data acquisition procedure and Matlab ${ }^{\circledR}$ for the data analysis processes. The performance and the effectiveness of the proposed measurement system were verified by an experimental validation procedure. Finally, the research approach was successfully accomplished, by developing a shaft alignment system with ultra-low cost with high degree of accuracy. The overall average standard deviation of the experimental data set was about $0.02 \mathrm{~mm}$, which is under the standard recommended values for alignment.
\end{abstract}

Keywor ds: Mis alignment, Induction Sensor, Rotating Machinery, Condition Based Maintenance (CBM).

DOI: $10.23881 /$ idupbo.018.1-7i 